\title{
Pain-related Somato Sensory Evoked Potentials: a potential new tool to improve the prognostic prediction of coma after cardiac arrest
}

\author{
Paolo Zanatta ${ }^{1 *}$, Federico Linassi², Anna Paola Mazzarolo², Maria Aricò², Enrico Bosco ${ }^{1}$, Matteo Bendini ${ }^{3}$, \\ Carlo Sorbara', Carlo Ori ${ }^{4}$, Michele Carron ${ }^{4}$ and Bruno Scarpa ${ }^{5}$
}

\begin{abstract}
Introduction: Early prediction of a good outcome in comatose patients after cardiac arrest still remains an unsolved problem. The main aim of the present study was to examine the accuracy of middle-latency SSEP triggered by a painful electrical stimulation on median nerves to predict a favorable outcome.
\end{abstract}

Methods: No- and low-flow times, pupillary reflex, Glasgow motor score and biochemical data were evaluated at ICU admission. The following were considered within $72 \mathrm{~h}$ of cardiac arrest: highest creatinine value, hyperthermia occurrence, EEG, SSEP at low- $(10 \mathrm{~mA})$ and high-intensity $(50 \mathrm{~mA})$ stimulation, and blood pressure reactivity to $50 \mathrm{~mA}$. Intensive care treatments were also considered. Data were compared to survival, consciousness recovery and 6-month CPC (Cerebral Performance Category).

Results: Pupillary reflex and EEG were statistically significant in predicting survival; the absence of blood pressure reactivity seems to predict brain death within 7 days of cardiac arrest. Middle- and short-latency SSEP were statistically significant in predicting consciousness recovery, and middle-latency SSEP was statistically significant in predicting 6-month CPC outcome. The prognostic capability of $50 \mathrm{~mA}$ middle-latency-SSEP was demonstrated to occur earlier than that of EEG reactivity.

Conclusions: Neurophysiological evaluation constitutes the key to early information about the neurological prognostication of postanoxic coma. In particular, the presence of $50 \mathrm{~mA}$ middle-latency SSEP seems to be an early and reliable predictor of good neurological outcome, and its absence constitutes a marker of poor prognosis. Moreover, the absence $50 \mathrm{~mA}$ blood pressure reactivity seems to identify patients evolving towards the brain death.

\section{Introduction}

Several efforts have been recently made to improve prognostication in comatose patients after cardiac arrest (CA). While the introduction of targeted temperature management (TTM) issues new challenges in interpreting clinical and neurophysiological findings [1-5], early prediction of a good outcome still remains an unsolved question. A multimodal approach combining clinical, biochemical, neurophysiological, and neuroimaging parameters was proposed to overcome the prognostic failure induced by TTM [6],

\footnotetext{
* Correspondence: pzanattalion@gmail.com

'Department of Anaesthesia and Intensive Care, Intraoperative and Critical Care Neurophysiology in Cardiac Surgery, Treviso Regional Hospital, Azienda Ospedaliera Ulss 9, Piazzale Ospedale 1, 31100 Treviso, Italy

Full list of author information is available at the end of the article
}

but it strengthened the accuracy only in predicting a poor outcome. Conversely, recent trials suggested the detection of continuous, reactive, spontaneous brain cortical activity to predict a good outcome [6-8], but unfortunately electroencephalogram (EEG) findings can suffer both from false positives and false negatives, reflecting the dynamism of acute brain damage, which can evolve toward the recovery from brain ischemia or toward worsening damage. False positive EEG finding (i.e., postanoxic status epilepticus in a patient who then recovers) are of critical value for the prognostication because they may discourage physicians from intensifying treatments $[9,10]$. Literature shows that in the acute phase after CA, the brain ischemia associated with hypothermia and pharmacological 
sedation may suppress reactivity and the cortical synaptic background transmission at different levels, hiding the existence of still-viable brain tissue but not functioning in a way that is typical of the ischemic penumbra [11-15].

How can the diagnostic tools in the early phase of postanoxic coma be improved? Neurophysiologists and neurocritical care physicians have recently shown interest in middle-latency somato sensory evoked potentials (MLSSEP), represented by cortical potentials in the range of 40-70 ms, because they reflect higher-order brain processes represented by cortical-cortical synaptic functions [16-19]. These synaptic functions seem to be required for recovery of consciousness and a good outcome [20-23]. It has also been attested that ML-SSEPs are more sensitive than short-latency SSEP (SL-SSEP, commonly named $\mathrm{N} 20 / \mathrm{P} 25)$ to the ischemic injury, and their preservation reflects a lower level of brain damage [24-26].

Furthermore, past studies showed that $40-70 \mathrm{~ms}$ potentials are localized in the para-Sylvian cortex near the lateral sulcus by the firing of the secondary somatosensory area (SII) and insula [27], that they can be activated by A delta nerve fibers $[28,29]$, and that they are involved in the cortical representation of pain [30]. Several years later we had the opportunity to replicate the causal effect of A delta conduction fiber on ML-SSEP generation; indeed, we suppressed $40-70$ ms potentials triggered by painful stimulus at $50 \mathrm{~mA}$ by blocking the median nerve sulcus with local anesthesia [11]. Moreover, we found that $50 \mathrm{~mA}$ ML-SSEP stimulation on the median nerves in anesthetized patients is associated with an increase in blood pressure, suggesting an autonomic response to stress $[11,31]$. In a preliminary report on a small cohort of postanoxic comatose patients, we showed that ML-SSEP and blood pressure (BP) reactivity triggered by painful electrical stimulations on the median nerves seem to predict, respectively, a good neurological outcome and survival [31]. Finally we attested that the same stimulation paradigm applied to functional magnetic resonance imaging (fMRI) can show the brain network involved in the detection of pain, also called the "pain matrix": SII, insula, and anterior cingulate cortex [32]. Prognostically, the presence of this neurophysiological cortical activity (and the respective neuroanatomical activity) demonstrates the functional integrity of a network that is multisensory, non-nociceptive-specific, and involved in the processing of salient sensory input related to motor preparation and emotional expression [33, 34]. In other words, in postanoxic coma, the persistence of ML-SSEPs after SL-SSEP reflects the functional integrity of connections that are involved in more complex processes than those of the primary somatosensory cortex (which are detected by SL-SSEPs). On the other hand, the absence of ML-SSEPs after SL-SSEP means that those areas involved in consciousness recovery lack functionality, thus predicting an evolution toward the minimally conscious state [32].
The target of this study is to compare ML-SSEP and $\mathrm{BP}$ reactivity triggered by high-intensity stimulation on the median nerves to all the most important clinical, biochemical and neurophysiological parameters that literature attests as early predictors of survival, consciousness recovery and good neurological outcome (i.e., awakening and Glasgow-Pittsburgh cerebral performance categories (CPC) 1-2).

\section{Methods \\ Subjects}

From July 2010 to August 2014, 167 postanoxic patients were admitted to ICUs at Treviso Regional Hospital (103 in the general ICU and 64 in the cardiac surgery ICU). As the major inclusion criterion for the present study was the availability of the EEG and SSEP within $72 \mathrm{~h}$ of CA, only 46 patients were retrospectively considered. All the neurophysiological evaluations were performed by the same neurophysiologist. None of these patients had previous neurological disease or sepsis. No distinction in recruitment was made for the place (in-hospital or out of hospital) or cause (cardiac or non-cardiac) of CA. The Lund University CA system (LUCAS) was used as a bridge for extracorporeal membrane oxygenation (ECMO) in patients not achieving the return of spontaneous circulation (ROSC) with conventional cardiopulmonary resuscitation (CPR). After ICU admission, patients were evaluated and subjected to TTM with Arctic Sun $\odot 5000$ (Medivance, Inc. 321 South Taylor Ave. Suite 200, Louisville, CO 80027), according to protocols described in the literature [35].

\section{Clinical and biochemical parameters}

Time from CA to ROSC was divided into no-flow (time from CA to CPR) and low-flow (time from CPR to ROSC or to the start of ECMO). The initial CA rhythm was categorized into ventricular tachycardia (VT), ventricular fibrillation (VF), pulseless electrical activity (PEA) and asystole (AS). Pupillary reflex (PR) and the Glasgow scale motor score $(\mathrm{M})$ were measured by the intensive care physician at ICU admission. First values of partial pressure of arterial oxygen $\left(\mathrm{PaO}_{2}\right)$, partial pressure of arterial carbon dioxide $\left(\mathrm{PaCO}_{2}\right), \mathrm{HCO}_{3}^{-}$, $\mathrm{pH}$, glucose and lactates at hospital admission were considered.

The occurrence of hyperthermia (tympanic temperature $>37.8{ }^{\circ} \mathrm{C}$ ) and the highest value of creatinine within $72 \mathrm{~h}$ of CA were also reported. Patients requiring pharmacological cardiovascular support were categorized according to three levels: low dosage (dopamine or dobutamine $\leq 4 \mu \mathrm{g} \cdot \mathrm{kg}^{-1} \cdot \mathrm{min}^{-1}$, noradrenaline (norepinephrine) $\leq 0.1 \mu \mathrm{g} \cdot \mathrm{kg}^{-1} \cdot \mathrm{min}^{-1}$, or adrenaline (epinephrine) $\leq 0.05 \mu \mathrm{g} \cdot \mathrm{kg}^{-1} \cdot \mathrm{min}^{-1}$ ), medium dosage (dopamine or dobutamine $>4^{-1}$ and $<8 \mu \mathrm{g} \cdot \mathrm{kg}^{-1} \cdot \mathrm{min}^{-1}$, 
noradrenaline $>0.1 \mu \mathrm{g} \cdot \mathrm{kg}^{-1} \cdot \mathrm{min}^{-1}$ and $<0.2 \mu \mathrm{g} \cdot \mathrm{kg}^{-1} \cdot \mathrm{min}^{-1}$, or adrenaline $>0.05 \mu \mathrm{g} \cdot \mathrm{kg}^{-1} \cdot \mathrm{min}^{-1}$ and $<0.1 \mu \mathrm{g} \cdot \mathrm{kg}^{-1} \cdot \mathrm{min}^{-1}$ ) and high dosage (dopamine or dobutamine $\geq 8 \mu \mathrm{g} \cdot \mathrm{kg}$ ${ }^{-1} \cdot \mathrm{min}^{-1}$, noradrenaline $\geq 0.2 \mu \mathrm{g} \cdot \mathrm{kg}^{-1} \cdot \mathrm{min}^{-1}$, or adrenaline $\left.\geq 0.1 \mu \mathrm{g} \cdot \mathrm{kg}^{-1} \cdot \mathrm{min}^{-1}\right)$.

\section{Neurophysiological evaluation}

Neurophysiological recordings were performed within $72 \mathrm{~h}$ after CA (at a mean of $33 \pm 22 \mathrm{~h}$ ) and consisted of EEG (background pattern and reactivity) and SSEP recorded in the same session. SSEP was performed by bilateral stimulation of the median nerves at $3.3 \mathrm{~Hz}$ using needle electrodes on both wrists. We considered two steps of electrical stimulation - low intensity $(10 \mathrm{~mA})$ and high intensity $(50 \mathrm{~mA})$ - to trigger the possible appearance of unilateral or bilateral cortical ML-SSEP. SL-SSEP was defined as present if the cortical N20/P25 response was present on one or both sides. SL-SSEP was defined as bilaterally absent if no reproducible potentials could be identified on either side at a maximum gain of $1 \mathrm{uV}$ per division in the presence of the brachial plexus potential. ML-SSEP was considered present if any reproducible potentials were detected on one or both sides in the range of 30-90 ms and with amplitude over $0.5 \mathrm{uV}$. Both SL and ML-SSEP were considered in the same recording window of $100 \mathrm{~ms}$. The high-intensity stimulation was also used to trigger EEG and BP reactivity. BP reactivity was considered significant if there was an increase of $10 \%$ over baseline values recorded at $10 \mathrm{~mA}$ stimulation. Muscleparalyzing medication (cisatracurium, $0.15 \mathrm{mg} \cdot \mathrm{kg}^{-1}$ ) was always used during the neurophysiological evaluation to reduce the noise induced by possible muscle artifacts. The ground electrode was placed on the left shoulder for both EEG and SSEP recordings. The impedance was kept below $1 \mathrm{k} \Omega$. EEG and SSEP were recorded using the NIMEclipse $^{\odot}$ Nerve Monitoring System (Medtronic Xomed, Jacksonville, FL, USA).

\section{EEG recording parameters and classification}

Eight bipolar EEG channels were recorded with needle electrodes placed at the standard scalp sites $(\mathrm{F} 3 / \mathrm{F} 4-\mathrm{Cz}$, C3'/C4'-Cz, T3/T4-Cz, P3/P4-Cz); in particular, C3' and C4' were placed $2 \mathrm{~cm}$ posterior to $\mathrm{C} 3$ and $\mathrm{C} 4$, according to the 10/20 international system. The EEG recording parameters were 1 and $40 \mathrm{~Hz}$ for low- and highfrequency filters, respectively, with a sampling rate of $250 \mathrm{~Hz}$ and hardware bandwidth of 1-100 Hz. EEG patterns were categorized by simplifying Cloostermans' classification [7] into three grades: grade 1, continuous pattern (diffuse slowing, normal); grade 2, epileptiform pattern; and grade 3, discontinuous pattern (isoelectric, burst suppression, low voltage). We chose this simplified EEG classification for statistical reasons and also because, in our opinion, it is easily interpreted by intensivists. EEG reactivity was considered if background patterns showed any reproducible change (acceleration or slowing, including amplitude variation) upon stimulation at $50 \mathrm{~mA}$.

\section{SSEP recording parameters}

Four bilateral SSEP channels were recorded within a time base of $100 \mathrm{~ms}$ : C4'/C3'-Fpz detected the SL (N20/ P25)-SSEP and the ML-SSEP; C4'/C3'-right Erb's point/ left Erb's point detected the interpeak between P14/N18 subcortical potential; $\mathrm{Cv}-\mathrm{Fpz}$ detected the N13 cervical potential; and right Erb's point/left Erb's point-Fpz detected the N9 brachial plexus potential. SSEP was doublefiltered at $30 \mathrm{~Hz}$ and $500 \mathrm{~Hz}$, respectively for low and high frequency filter. Each trace averaged 100 sweeps; a minimum of three traces were taken during every step. Each step of stimulation lasted $90 \mathrm{~s}$ after rejection of trials due to possible artifacts. The stimulus duration was lengthened from $200 \mu \mathrm{s}$ in the first series of 17 patients [29] to $1000 \mu \mathrm{s}$ in the remaining patients to increase the possible activation of the A $\delta$ nerve fibers $[36,37]$.

\section{Outcome evaluation}

Recovery of consciousness was defined as the ability to repeatedly carry out simple commands to more than one physician. CPC outcome evaluation was performed at 6 months after a medical and neurological examination; in the same session, patients were subjected to a neuropsychological evaluation, the results of which were not considered for the following study. Outcome was classified as good (CPC 1-2, corresponding to no or moderate neurological disability), and poor (CPC 3-4-5, corresponding to a severe disability, coma and death).

\section{Decision to treat}

Status epilepticus with normal SL-SSEP was treated only after the neurophysiological evaluation, using incremental doses of midazolam $\left(0.03-0.2 \mathrm{mg} \cdot \mathrm{kg}^{-1} \cdot \mathrm{h}^{-1}\right)$ with or without propofol $\left(3-10 \mathrm{mg} \cdot \mathrm{kg}^{-1} \cdot \mathrm{h}^{-1}\right)$; the most resistant patients were additionally treated with thiopental to achieve the burst suppression pattern for $48 \mathrm{~h}$. Levetiracetam ( $1 \mathrm{~g}$ twice daily) was also used to replace continuous sedation; additional antiepileptic medications were given according to EEG patterns. In patients with bilaterally absent cortical SSEP, malignant unreactive EEG patterns and absent brainstem reflexes, the decision to withdraw supportive care was taken at a physician's discretion. Patients who persisted in a comatose state for more than 15 days despite the presence of SL-SSEP or SL/ML-SSEP were subjected to brain fMRI with the same stimulation paradigm of the pain-related SSEP to endorse the evoked potential evaluation. 


\section{Ethics}

The use of pain is a paradox in the medical practice; while, on one hand, it must be treated to reduce suffering and stress response, on the other hand, it is widely used to explore consciousness in comatose patients. Indeed, the intensivists use the Glasgow coma scale (GCS) daily to investigate consciousness status [38]. Since 2010, our institution has replaced the use of GCS with pain-related (50 mA) SSEP in postanoxic coma, as compared to the GCS, SSEP requires less frequent painful stimulations (at most two stimulations with a 180-s duration) in the first $72 \mathrm{~h}$ and represents a more sensitive method to explore brain function (brain somatosensory afferent pathway reactivity versus the efferent motor response of the GCS, which is often blunted by sedation) [31]. As pain is considered an unpleasant experience that involves the conscious awareness of noxious sensations [39], the painful somatic (GCS) or neurophatic (pain-related SSEP) stimulations seem to be ineffective during deep coma, sedation and concomitant global disorders of the EEG signals; none of the patients experience a conscious awareness of noxious sensations. Moreover, in some circumstances, the pain-related ML-SSEP associated with severe EEG disorders can induce the physician to continue therapies instead of abandoning them. Relatives of the patients were always made aware of the use of this additional technique. All procedures performed in this study was in accordance with the ethical standards of the institutional and/or national research committee and with the 1964 Helsinki declaration and its later amendments or comparable ethical standards. For this retrospective type of study formal consent is not required. The manuscript was approved by the Provincial Ethics Committee of Treviso (N. 11; record 852/14).

\section{Statistical analysis}

All recorded parameters were related to three outcome categories (survival, recovery of consciousness, and CPC at 6 months after $\mathrm{CA}$ ) and divided into two outcome levels (good outcome (CPC 1-2) and poor outcome (CPC 3-5)). To describe the general characteristics of the study population, absolute and relative frequencies were calculated for qualitative data, and mean and standard deviation were calculated for quantitative values (Table 1). To estimate which variables are related to mortality, recovery of consciousness, or 6-month CPC outcomes, Pearson's chi-square test was calculated for qualitative data and the Mann-Whitney test was calculated for quantitative data. To estimate whether TTM and sedation were associated with EEG reactivity, SL-SSEP and ML-SSEP, or BP reactivity, Student's $t$ test was performed. The Wilcoxon signed-rank test was performed to evaluate whether there were significant differences between $50 \mathrm{~mA}$ ML-SSEP, EEG reactivity appearance time, and time of best motor response among patients who had 10 or $50 \mathrm{~mA}$ ML-SSEP or EEG reactivity. To investigate whether the presence of unilateral or bilateral ML-SSEP is associated with CPC, Pearson's Chi-square test was calculated. Relative risk (RR) was calculated to investigate the efficacy of TTM, intra-aortic balloon pumps (IABPs), ECMO, continuous veno-venous hemofiltration (CVVH), coronarography, and inotropic drugs; among out-ofhospital (OHCA) patients, the same test was used to determine if there were significant outcome differences for patients hospitalized in the general and cardiac surgery ICUs. Given the large number of comparisons conducted on the same data and the large number of variables analyzed, we performed the Holm [40] correction for multiple comparisons, which is less conservative than the more frequently used Bonferroni correction. A $p$ value $<0.05$ was considered to be statistically significant. To investigate which variables added significant predictive capacity, for each output variable, we fitted a logistic regression model by selecting relevant variables through a cross-validated stepwise selection procedure. Given the small dataset and the high co-linearity of many variables, we estimated the logistic regression parameters using a bias-reduction maximum-likelihood method [41, 42]. Leave-one-out cross-validation was implemented at each step of the forward selection procedure to choose the best set of predictors for each output variable. Statistical analysis was performed with IBM SPSS Statistics for Windows, Version 19.0 (IBM Corp., Armonk, NY, USA) and with $\mathrm{R}$ [43].

\section{Results}

\section{Survival outcome}

During hospitalization, 22 of 46 patients (48\%, $95 \%$ CI 34.13-61.87 \%) survived; all survivors had BP reactivity. Of those patients who did not survive, 9 (9.57\%, $95 \%$ CI 10.65-33.18\%) had no BP reactivity and died within 7 days because of brain death; the other 15 patients (32.61 \%, 95 \% CI 20.87-47.03 \%) died because of extraneurological causes (Fig. 1).

Pearson's chi-square test (corrected for multiple comparisons) attested that two variables were statistically significant to predict a fatal outcome at 6 months: pupillary reflex $(p<0.005)$ and simplified EEG patterns $(p<0.05)$, as shown in Tables 2 and 3 . None of the results for analysis of the quantitative variables were statistically significant once the $p$ values were corrected for multiple comparisons $(p<0.05)$.

The results of the logistic regression model show that the only relevant variable to predict a fatal outcome is the PR (odds ratio 23.399). The receiver operator characteristic (ROC) curve of such a model is plotted in the first panel of Fig. 2, and the area under the ROC curve (AUC) is 0.8371 . 
Table 1 General characteristics of the population

\begin{tabular}{|c|c|c|c|}
\hline Characteristic & Arithmetic mean & Value standard deviation & Minimum-Maximum \\
\hline Age (years) & 59.37 & 14.43 & $20-89$ \\
\hline Time no-flow (minutes) & 7.67 & 26.03 & $4-110$ \\
\hline Partial pressure of arterial $\mathrm{O}_{2}(\mathrm{mmHg})$ & 138.86 & 112.44 & $25.8-539$ \\
\hline Partial pressure of arterial $\mathrm{CO}_{2}(\mathrm{mmHg})$ & 48.92 & 12.91 & $21.1-81.1$ \\
\hline $\mathrm{HCO}_{3}^{-}(\mathrm{mmol} / \mathrm{L})$ & 14.85 & 4.75 & $7-27.4$ \\
\hline $\mathrm{Ph}$ & 7.13 & 0.14 & $6.87-7.41$ \\
\hline Glycemia (mg/dL) & 307.15 & 97.84 & $114-627$ \\
\hline Lactates (mmol/L) & 9.87 & 4.05 & $2.4-20$ \\
\hline Highest creatinine during $72 \mathrm{~h}(\mathrm{mg} / \mathrm{dL})$ & 1.84 & 1.12 & $0.64-4.8$ \\
\hline Characteristic & Absolute frequency Number & Value relative frequency $\%$ & Cl $95 \%$ \\
\hline Ventricular fibrillation rhythm of cardiac arrest & 32 & 69.57 & $55.20-80.92$ \\
\hline Pulseless electrical activity rhythm of cardiac arrest & 8 & 17.39 & $9.08-30.72$ \\
\hline Asystole rhythm of cardiac arrest & 6 & 13.04 & $6.12-25.66$ \\
\hline Cardiac arrest due to cardiac cause & 32 & 69.57 & $55.20-80.92$ \\
\hline Cardiac arrest due to non-cardiac cause & 14 & 30.43 & $19.08-44.80$ \\
\hline Patients with out-of-hospital cardiac arrest & 35 & 76.09 & $62.07-86.09$ \\
\hline Patients with in-hospital cardiac arrest & 11 & 23.91 & $13.91-37.93$ \\
\hline LUCAS $^{\text {TM }}$ patients & 11 & 23.91 & $13.91-37.93$ \\
\hline Not LUCAS ${ }^{T M}$ patients & 35 & 76.09 & $62.07-86.09$ \\
\hline General ICU patients & 18 & 39.13 & $26.39-53.54$ \\
\hline Heart surgery ICU patients & 28 & 60.87 & $46.46-73.61$ \\
\hline Low-dosage patient's intravascular drug support & 10 & 21.74 & $12.26-35.57$ \\
\hline Medium-dosage patient's intravascular drug support & 9 & 19.57 & $10.65-33.18$ \\
\hline High-dosage patient's intravascular drug support & 27 & 58.70 & $44.34-71.72$ \\
\hline Patients with intra-aortic balloon pump & 16 & 34.78 & $22.68-49.23$ \\
\hline Patients with no intra-aortic balloon pump & 30 & 65.22 & $50.77-77.32$ \\
\hline Patients who had coronary angiography & 28 & 60.87 & $46.46-73.61$ \\
\hline Patients who did not have coronary angiography & 18 & 39.13 & $26.39-53.54$ \\
\hline Percutaneous transluminal coronary angioplasty/stent & 12 & 26.09 & $15.60-40.26$ \\
\hline No percutaneous transluminal coronary angioplasty/stent & 34 & 73.91 & $59.74-84.40$ \\
\hline Patients on continuous veno-venous hemofiltration & 16 & 34.78 & $22.68-49.23$ \\
\hline Patients not on continuous veno-venous hemofiltration & 30 & 65.22 & $50.77-77.32$ \\
\hline Patients on extracorporeal membrane oxygenation & 8 & 17.39 & $9.08-30.72$ \\
\hline Patients not on extracorporeal membrane oxygenation & 38 & 82.61 & $69.28-90.92$ \\
\hline Patients on target temperature management & 23 & 50.00 & $36.12-63.88$ \\
\hline Patients not on target temperature management & 23 & 50.00 & $36.12-63.88$ \\
\hline Patients on target temperature management in $<2 \mathrm{~h}$ & 7 & 30.43 & $15.60-50.86$ \\
\hline Patients on target temperature management in $>2 \mathrm{~h}$ & 16 & 69.57 & $49.14-84.40$ \\
\hline Temperature $\geq 37.8$ after $24 \mathrm{~h}^{\mathrm{a}}$ & 20 & 47.62 & $33.36-62.28$ \\
\hline Temperature $<37.8$ after $24 \mathrm{~h}^{\mathrm{a}}$ & 22 & 52.38 & $37.72-66.64$ \\
\hline Pupillary reflex $+{ }^{a}$ & 24 & 57.14 & $42.20-70.88$ \\
\hline Pupillary reflex $-^{\mathrm{a}}$ & 18 & 42.86 & $29.12-57.80$ \\
\hline First evaluation of motor response $\leq \mathrm{M} 2$ & 39 & 84.78 & $71.77-92.43$ \\
\hline First evaluation of motor response $>M 2$ & 7 & 15.22 & $7.57-28.23$ \\
\hline
\end{tabular}


Table 1 General characteristics of the population (Continued)

\begin{tabular}{|c|c|c|c|}
\hline Isoelectric electroencephalogram & 10 & 21.74 & $12.26-35.57$ \\
\hline Burst Suppression electroencephalogram & 3 & 6.52 & $2.24-17.50$ \\
\hline Low voltage electroencephalogram & 4 & 8.70 & $3.44-20.33$ \\
\hline Epileptiform electroencephalogram & 8 & 17.39 & $9.08-30.72$ \\
\hline Diffuse slowing electroencephalogram & 17 & 36.96 & $24.53-51.40$ \\
\hline Normal electroencephalogram & 4 & 8.70 & $3.44-20.33$ \\
\hline Discontinuous electroencephalogram patterns & 17 & 36.96 & $24.53-51.40$ \\
\hline Epileptiform electroencephalogram & 8 & 17.39 & $9.08-30.72$ \\
\hline Continuous electroencephalogram patterns & 21 & 45.65 & $32.15-59.82$ \\
\hline Electroencephalogram reactivity & 10 & 21.74 & $12.26-35.57$ \\
\hline Electroencephalogram unreactivity & 36 & 78.26 & $64.43-78.26$ \\
\hline Short-latency somatosensory evoked potentials + & 29 & 63.04 & $48.60-75.47$ \\
\hline Short-latency somatosensory evoked potentials - & 17 & 36.96 & $24.53-51.40$ \\
\hline 10 mA Middle-latency somatosensory evoked potentials + & 9 & 19.57 & $10.65-33.18$ \\
\hline 10 mA Middle-latency somatosensory evoked potentials - & 37 & 80.43 & $66.82-89.35$ \\
\hline 50 mA Middle-latency somatosensory evoked potentials + & 19 & 41.30 & $28.28-55.66$ \\
\hline 50 mA Middle-latency somatosensory evoked potentials - & 27 & 58.70 & $44.34-71.72$ \\
\hline $50 \mathrm{~mA}$ Blood pressure reactivity + & 37 & 80.43 & $66.82-89.35$ \\
\hline $50 \mathrm{~mA}$ Blood pressure reactivity -columns & 9 & 19.57 & $10.65-33.18$ \\
\hline Sedation during Neurophysiological recordings & 22 & 52.38 & $37.72-40.26$ \\
\hline $\begin{array}{l}\text { Target temperature management during Neurophysiological } \\
\text { recordings }\end{array}$ & 12 & 26.09 & $15.60-40.26$ \\
\hline
\end{tabular}

${ }^{\mathrm{a}}$ Missing data for four patients. LUCAS Lund University cardiac arrest system

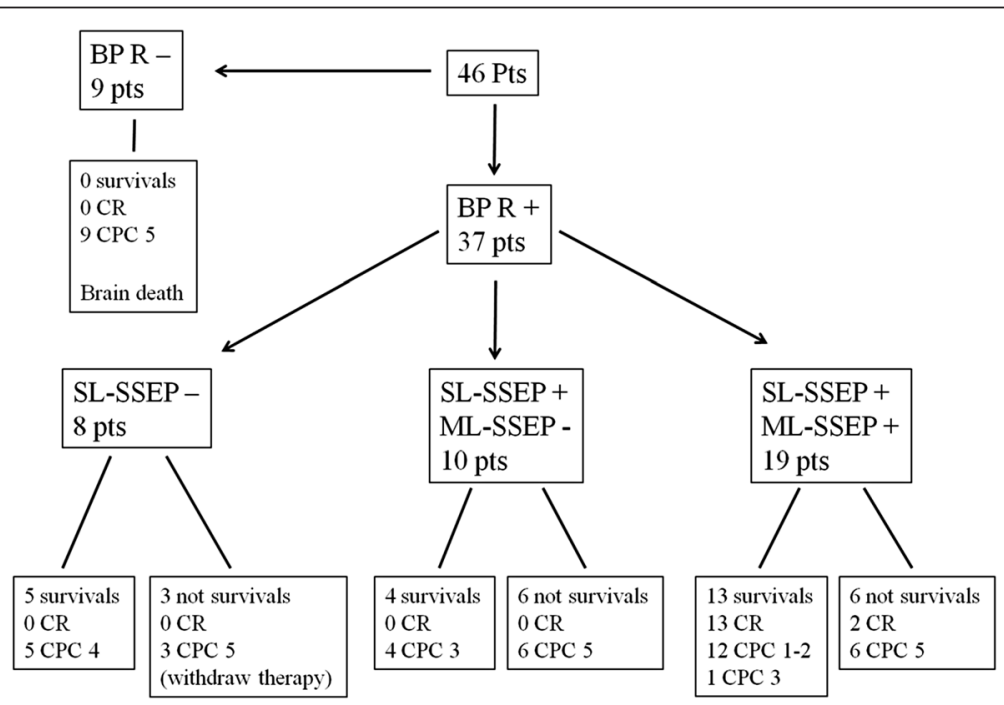

Fig. 1 Distribution of patients on the outcome levels (survival, recovery of consciousness (CR) and cerebral performance category (CPC)) based on blood pressure reactivity (BP-R), short-latency somatosensory evoked potentials SL-SSEP and middle-latency SSEP (ML-SSEP). Of the patients, 6 with SL-SSEP and without $50 \mathrm{~mA} \mathrm{ML-SSEP}$ died because of heart failure $(n=2)$, sepsis $(n=2)$ or bronchopneumonia $(n=2) ; 6$ patients with SL-SSEP and 50 mA ML-SSEP died because of cardiogenic shock $(n=3)$, septic shock $(n=1)$, pulmonary hemorrhage $(n=1)$ or multiple organ failure $(n=1)$ 
Table 2 Statistically significant variables

\begin{tabular}{|c|c|c|c|c|c|c|c|c|c|c|}
\hline Variable & Significant outcome & $P$ value & Sensitivity \% & Cl $95 \%$ & Specificity \% & Cl $95 \%$ & PPV \% & Cl $95 \%$ & NPV \% & Cl $95 \%$ \\
\hline Pupillary reflex & Survival & $<0.005$ & 76.19 & $52.83-91.69$ & 90.48 & $69.58-98.55$ & 88.89 & $65.25-98.30$ & 79.17 & $57.84-92.79$ \\
\hline $\begin{array}{l}\text { Continuous } \\
\text { EEG patterns }\end{array}$ & Survival & $<0.05$ & 70.83 & $48.91-87.33$ & 63.64 & $40.67-82.76$ & 68.00 & $46.50-85.01$ & 66.67 & $43.04-85.35$ \\
\hline $\begin{array}{l}\text { Epileptiform } \\
\text { EEG pattern }\end{array}$ & Survival & $<0.05$ & 91.67 & $72.96-98.73$ & 27.27 & $10.80-50.22$ & 57.89 & $40.83-73.68$ & 75.00 & $35.05-96.07$ \\
\hline $\begin{array}{l}\text { Discontinuous } \\
\text { EEG patterns }\end{array}$ & Survival & $<0.05$ & 62.50 & $40.60-81.16$ & 90.91 & $70.80-98.62$ & 88.24 & $63.52-98.20$ & 68.97 & $49.17-84.68$ \\
\hline $\begin{array}{l}\text { ML-SSEP at } \\
50 \mathrm{Ma}\end{array}$ & $\begin{array}{l}\text { Consciousness } \\
\text { recovery }\end{array}$ & $<0.001$ & 87.10 & $70.15-96.29$ & 100.00 & $78.03-100.00$ & 100.00 & $87.11-100.00$ & 78.95 & $54.43-93.82$ \\
\hline SL-SSEP & $\begin{array}{l}\text { Consciousness } \\
\text { recovery }\end{array}$ & $<0.05$ & 54.84 & $36.04-72.67$ & 100.00 & $78.03-100.00$ & 100.00 & $80.33-100.00$ & 51.72 & $32.54-70.54$ \\
\hline $\begin{array}{l}\text { ML-SSEP at } \\
50 \mathrm{Ma}\end{array}$ & 6 months CPC & $<0.005$ & 79.41 & $62.09-91.26$ & 100.00 & $73.35-100.00$ & 100.00 & $87.11-100.00$ & 63.16 & $38.38-83.65$ \\
\hline
\end{tabular}

PPV positive predictive value, NPV negative predictive value, EEG electroencephalogram, ML-SSEP middle-latency somatosensory evoked potentials, SL-SSEP short-latency somatosensory evoked potentials, CPC cerebral performance category

\section{Recovery of consciousness outcome}

A total of 15 patients (32.61\%, $95 \%$ CI 20.87-47.03\%) regained consciousness. All of them had SL-SSEP and $50 \mathrm{~mA}$ ML-SSEP; however, 2 of these 15 patients (13.33\%, 95 \% CI 3.73-37.88 \%) died during hospitalization because of non-neurological causes (Fig. 1), and 1 patient (6.67 \%, $95 \%$ CI 1.19-29.82 \%) had CPC 3 at 6 months. Of the 31 patients $(87.10 \%, 95 \%$ CI 71.15-94.87 \%) who did not regain consciousness, 27 did not have $50 \mathrm{~mA}$ ML-SSEP; the other 4 patients $(12.90 \%, 95 \%$ CI $5.13-28.85 \%)$ died during hospitalization without recovery of consciousness because of non-neurological causes (Fig. 1).

Pearson's chi-square test (after Holm's correction for multiple comparisons) attested that two variables were statistically significant to predict recovery of consciousness: $50 \mathrm{~mA}$ ML-SSEP $(p<0.001)$ and SL-SSEP $(\mathrm{N} 20 / \mathrm{P} 25$;

Table 3 Significant parameters in the population categorized according to mortality, consciousness recovery and CPC at 6 months

\begin{tabular}{|c|c|c|c|c|c|c|c|}
\hline \multirow[t]{2}{*}{ Characteristic } & \multicolumn{3}{|l|}{ Survivors } & \multicolumn{3}{|l|}{ Non survivors } & \multirow[t]{2}{*}{$P$ value* } \\
\hline & $\begin{array}{l}\text { Absolute frequency } \\
\text { Number }\end{array}$ & $\begin{array}{l}\text { Relative } \\
\text { frequency \% }\end{array}$ & Cl $95 \%$ & $\begin{array}{l}\text { Absolute frequency } \\
\text { number }\end{array}$ & $\begin{array}{l}\text { Relative } \\
\text { frequency \% }\end{array}$ & $\mathrm{Cl} 95 \%$ & \\
\hline Pupillary reflex $+{ }^{a}$ & 19 & 45.24 & $31.23-60.05$ & 5 & 11.90 & 5.19-24.99 & $<0.005$ \\
\hline Pupillary reflex - ${ }^{\mathrm{a}}$ & 2 & 4.76 & $1.31-15.79$ & 16 & 38.10 & $25.00-53.19$ & \\
\hline $\begin{array}{l}\text { Discontinuous EEG } \\
\text { patterns }\end{array}$ & 2 & 4.35 & $1.20-14.54$ & 15 & 32.61 & $20.87-47.03$ & $<0.05$ \\
\hline Epileptiform EEG & 6 & 13.04 & $6.12-25.66$ & 2 & 4.35 & $1.20-14.54$ & \\
\hline $\begin{array}{l}\text { Continuous EEG } \\
\text { patterns }\end{array}$ & 14 & 30.43 & $19.08-44.80$ & 7 & 15.22 & $7.57-28.23$ & \\
\hline \multirow[t]{2}{*}{ Characteristic } & \multicolumn{3}{|c|}{ Consciousness recovery } & \multicolumn{3}{|c|}{ No consciousness recovery } & $P$ value ${ }^{*}$ \\
\hline & $\begin{array}{l}\text { Absolute frequency } \\
\text { number }\end{array}$ & $\begin{array}{l}\text { Relative } \\
\text { frequency \% }\end{array}$ & $\mathrm{Cl} 95 \%$ & $\begin{array}{l}\text { Absolute frequency } \\
\text { number }\end{array}$ & $\begin{array}{l}\text { Relative } \\
\text { frequency \% }\end{array}$ & $\mathrm{Cl} 95 \%$ & \\
\hline SL-SSEP + & 15 & 32.61 & $20.87-47.03$ & 14 & 30.43 & $19.08-44.80$ & $<0.05$ \\
\hline SL-SSEP - & 0 & 0.00 & $0.00-8.38$ & 17 & 36.96 & $24.53-51.40$ & \\
\hline $50 \mathrm{~mA}$ ML-SSEP + & 15 & 32.61 & $20.87-47.03$ & 4 & 8.70 & $3.44-20.33$ & $<0.001$ \\
\hline 50 mA ML-SSEP - & 0 & 0.00 & $0.00-8.38$ & 27 & 58.70 & $44.34-71.72$ & \\
\hline \multirow[t]{2}{*}{ Characteristic } & \multicolumn{3}{|l|}{ CPC 1-2 } & \multicolumn{3}{|l|}{ CPC $3-5$} & $P$ value ${ }^{*}$ \\
\hline & $\begin{array}{l}\text { Absolute frequency } \\
\text { number }\end{array}$ & $\begin{array}{l}\text { Relative } \\
\text { frequency \% }\end{array}$ & $\mathrm{Cl} 95 \%$ & $\begin{array}{l}\text { Absolute frequency } \\
\text { number }\end{array}$ & $\begin{array}{l}\text { Relative } \\
\text { frequency \% }\end{array}$ & Cl $95 \%$ & \\
\hline 50 mA ML-SSEP + & 12 & 26.09 & $15.60-40.26$ & 7 & 15.22 & $7.57-28.23$ & $<0.005$ \\
\hline 50 mA ML-SSEP - & 0 & 0.00 & $0.00-8.38$ & 27 & 58.70 & $44.34-71.72$ & \\
\hline
\end{tabular}

${ }^{*} P$ value with Holm correction. ${ }^{a}$ Missing data for 4 patients. EEG electroencephalogram, ML-SSEP middle-latency somatosensory evoked potentials, SL-SSEP short-latency somatosensory evoked potentials, CPC cerebral performance category 

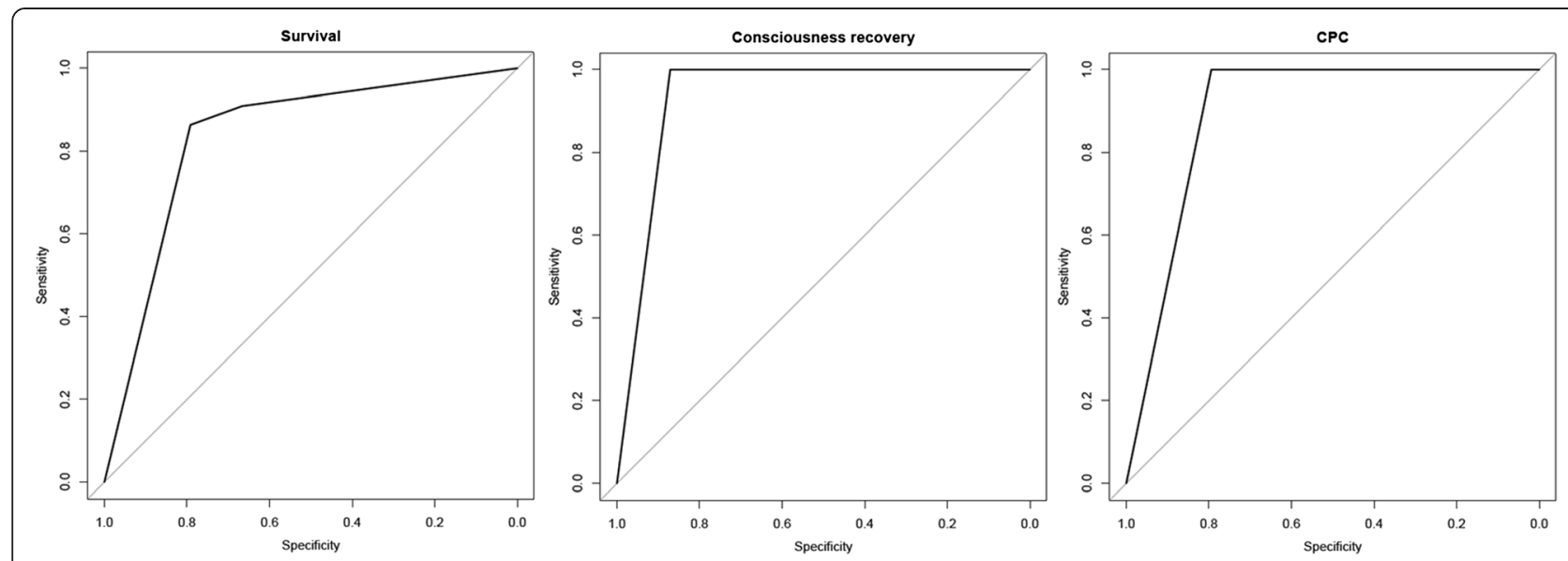

Fig. 2 Receiver operator characteristic (ROC) curves for the three final logistic models. First panel (left): pupillary reflex ROC curve for survival; second panel (middle): $50 \mathrm{~mA}$ middle latency somatosensory evoked potentials (ML-SSEP) ROC curve for consciousness recovery; third panel (right): $50 \mathrm{~mA}$ ML-SSEP ROC curve for the 6-month cerebral performance category

$p<0.05)$, as shown in Tables 2 and 3. The results from the logistic regression model show that only $50 \mathrm{~mA} \mathrm{ML-}$ SSEP was relevant in predicting a poor outcome (odds ratio 189.43). The ROC curve of such a model is plotted in the second panel of Fig. 2, and the AUC was 0.9355.

\section{CPC outcome}

At 6 months, 12 of 46 patients $(26.09 \%, 95 \%$ CI $15.60-40.26 \%)$, that is, 12 of $13(92.31 \%, 95 \%$ CI 66.69-98.63\%) patients who regained consciousness and survived, had a CPC of 1 or 2 . All of them had SLSSEP and $50 \mathrm{~mA}$ ML-SSEP. Of the 34 patients (79.41 \%, $95 \%$ CI 63.20-89.65 \%) who had CPC 3-5, 27 did not have $50 \mathrm{~mA}$ ML-SSEP; 6 of these 34 patients (17.65 \%, $95 \%$ CI 8.35-33.52 \%) had $50 \mathrm{~mA}$ ML-SSEP but had CPC 5 because they died during hospitalization ( 2 of them after recovery of consciousness); only 1 patient $(2.94 \%, 95 \%$ CI $0.52-14.91 \%)$ had $50 \mathrm{~mA} \mathrm{ML-}$ SSEP but had CPC 3 at 6 months - this patient regained consciousness during hospitalization but ultimately evolved into a minimally conscious state (Fig. 1). No patient who was alive at ICU discharge died before the 6-month follow up.

Pearson's chi-square test (after applying Holm's correction for multiple comparisons) attested that only $50 \mathrm{~mA}$ ML-SSEP was statistically significant $(p<0.005)$ in predicting CPC (Tables 2 and 3). The results from the logistic regression model show that only $50 \mathrm{~mA}$ ML-SSEP was relevant in predicting CPC (odds ratio 91.65). The ROC curve of such a model is plotted in the second panel of Fig. 2, and the AUC was 0.8971.

\section{Additional analysis}

The time to the appearance of ML-SSEP was statistically lower than the time to the appearance of EEG reactivity ( $22 \pm 12$ vs. $196 \pm 78 \mathrm{~h}$, respectively, $p<0.005)$ and was also lower than the time to the best Glasgow motor score $(266 \pm 304 \mathrm{~h}, p<0.001)$. Sedation and TTM did not influence the neurophysiological recordings. TTM did not prevent hyperthermia within $72 \mathrm{~h}$.

\section{ML-SSEP distribution among the sample}

Of the 19 patients who had ML-SSEP, 9 (47.37 \%, $95 \%$ CI 27.33-68.29 \%) showed ML-SSEP at both 10 and $50 \mathrm{~mA}$, and 10 (52.63\%, $95 \%$ CI 31.71-72.67\%) had ML-SSEP only at $50 \mathrm{~mA}$ stimulation. The 9 patients who presented with $10 \mathrm{~mA}$ ML-SSEP had bilateral $(\mathrm{n}=3)$, right $(\mathrm{n}=3)$ and left $(\mathrm{n}=3)$ ML-SSEP. The 10 patients who presented with only $50 \mathrm{~mA}$ ML-SSEP had bilateral $(n=7)$, right $(n=2)$ and left $(n=1)$ MLSSEP. Pearson' chi-square test attested that the presence of unilateral or bilateral ML-SSEP had no effect on predicting 6-month CPC.

\section{Discussion}

This study suggests that the combination of a few neurophysiological and clinical parameters is useful to quickly stratify the prognosis of coma after CA $(33 \pm 22 \mathrm{~h})$. In particular, PR and EEG patterns predict survival at 6 months, and the absence of BP reactivity seems to be related to brain death within 1 week. SL-SSEP and $50 \mathrm{~mA}$ ML-SSEP predicted consciousness recovery, and $50 \mathrm{~mA}$ ML-SSEP predicted CPC outcome at 6 months. The prognostic capability of $50 \mathrm{~mA}$ ML-SSEP occurred earlier than that of EEG reactivity. All of these parameters can be considered brain-damage-related indexes. Our data also showed that soon after CA the GCS has poor prognostic capability with respect to the neurophysiological parameters. 
We find it more useful to stratify the level of good outcomes (in recovery of consciousness and CPC 1-2) at 6 months than to record only the best CPC score at any time within the first 6 months after CA [7], as recovery of consciousness reflects the end of coma caused by lower anoxic injury. As $50 \mathrm{ML}-\mathrm{SSEP}$ can quickly detect lower anoxic injury, it is important to focus therapies in these patients who can regain consciousness and eventually have a CPC of $1-2$. In other words, having ML-SSEP does not necessarily imply a good outcome. A good outcome could be primarily related to the concomitant pathologies. Indeed, in our series, among those with $50 \mathrm{~mA}$ ML-SSEP, 7 patients did not have CPC of $1-2$ at 6 months: 6 patients died during hospitalization ( 2 after recovery of consciousness, see Fig. 1), and 1 regained consciousness but had CPC 3 at 6 months - we suspect that this patient suffered from untreated status epilepticus, because the EEG reports during the rehabilitation time underlined a poor quality of recording due to many supposed muscular artifacts.

\section{Predictors of survival}

Our overall mortality rate is lower than the rates from other recent series (48\%, vs. $70 \%$ [44]), and is similar to the rate in the 1950s [45]; this difference can be explained by considering neurophysiological decisions to withdraw treatments in other trials $[2,6]$. By contrast, in our hospital, an increased number of patients survived in a permanent vegetative state (PVS).

PR at ICU admission (recorded independently of TTM) seems to be the only parameter related to survival at 6 months, as the early absence of this brainstem reflex suggests a deep impairment of the central nervous system; however, this measure is less reliable than $72 \mathrm{~h} \mathrm{PR}$ (10 \% FPR vs. 0-4 \%) [2, 3]. Interestingly, an absence of $\mathrm{BP}$ reactivity seems to constitute a marker of brain death within 1 week (specificity $100 \%$ ). These data are in line with Fugate's [46] findings, in which the loss of cardiovascular regulation was related to brain death within one week. Moreover, patients with BP reactivity and absent PR who died after 1 week did so due to non-neurological causes. Interestingly, $\mathrm{BP}$ reactivity and $\mathrm{PR}$ seem to be related to the timing of death in our sample, probably because they are the expression of different levels of subcortical dysfunction, in the brain stem and the midbrain, respectively. We found, as shown in previous data [31], that $\mathrm{BP}$ reactivity was useful to stratify prognosis among patients with absent SL-SSEP into those who will die and those who could survive with a poor outcome (CPC 4).

\section{Predictors of consciousness recovery and CPC 1-2 at 6 months}

Only SSEP evaluation was statistically significant in predicting recovery of consciousness and good CPC at
6 months. EEG was not statistically significant, but malignant EEG patterns had good specificity (93\% for consciousness and $100 \%$ for $\mathrm{CPC}$ ) in predicting a poor outcome. Most of the patients who regained consciousness (11 out of 15) and who had a good outcome (9 out of 12) had a continuous pattern, which is in line with the findings of Cloostermans et al. [7] and Rossetti [2]. Preservation of cortical synaptic transmission is the most critical factor in early recovery; however, specificity is not high (73\% for consciousness and $75 \%$ for CPC), probably because of brain ischemia rather than TTM or sedation, based on early (33 h from CA) recordings [9, 10, 13, 15]. Indeed, our data showed that TTM $\left(33-34{ }^{\circ} \mathrm{C}\right)$ and sedation did not change EEG and SSEP at all, reinforcing the fact that the greatest determinant of brain dysfunction both in intensive care [47] and in the operating room [48] is brain ischemia. Moreover, hypnotic sedation (e.g., midazolam and propofol) does not attenuate pain-related ML-SSEPs (like opioids do), as ML-SSEPs seem to be the neurophysiological expression of the activation of the brain-area network involved both in pain perception $[11,32]$ and other salient sensory input [33].

We confirm the published data on SL-SSEP [49]: absent N20/P25 relates to lack of conscious recovery (100\% specificity) while present N20/P25 $\left(\right.$ SL-SSEP $^{+}$) is not sensitive enough (55\% and $50 \%$ ) to predict a good neurological outcome. SSEP can explore both the primary somatosensory cortex (by SL-SSEP) and the secondary cortex (by ML-SSEP) in the range of $40-70 \mathrm{~ms}[17,18]$. ML-SSEP can be triggered by a $10 \mathrm{~mA}$ (9 patients) or $50 \mathrm{~mA}$ (19 patients) stimulus on median nerves. It is not unusual that ML-SSEP can also be activated by a lowintensity $(10 \mathrm{~mA})$ stimulus due to the salience of the electrical stimulus, thus assuming a lower extension of brain damage. However, $50 \mathrm{~mA}$ ML-SSEP has similar sensitivity ( $87 \%$ vs. $90 \%$ and $79 \%$ vs. $88 \%$ ) but higher specificity (100\% vs. $40 \%$ and $100 \%$ vs. $42 \%$ ) than $10 \mathrm{~mA} \mathrm{ML-}$ SSEP in predicting recovery of consciousness and CPC 1-2 at 6 months, respectively. Indeed, by stressing (at $50 \mathrm{~mA}$ ) the somatosensory system and activating pain A $\delta$ fibers, it is possible to explore the brain tissue that is still viable but not functioning, favoring the appearance of evoked cortical-cortical interactions (ML-SSEP) independent of the spontaneous cortical EEG reactivity, which is often suppressed by the brain ischemic penumbra (Fig. 3).

In our opinion, in the early phase of the postanoxic coma, the interpretation of SSEP reactivity seems to be simpler and more effective than that of EEG reactivity.

\section{Technical and procedural aspects}

Muscle relaxant medication, which hides clinical evaluation, is a fundamental prerequisite to improve the reliability of neurophysiological evaluation by increasing the signal-to-noise ratio [31, 32], as greater noise might 


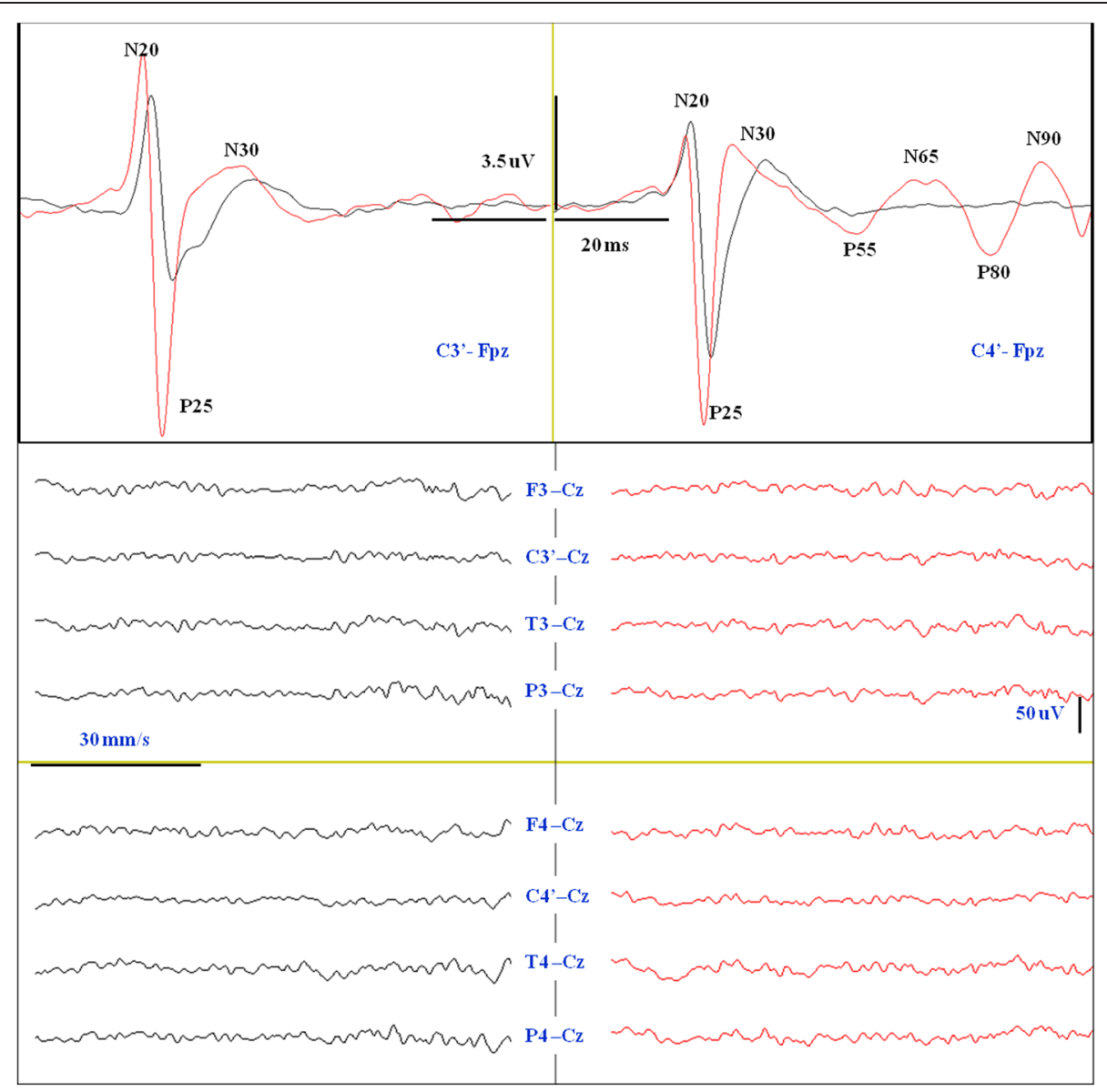

Fig. 3 Somatosensory evoked potentials (SSEP) recording at $12 \mathrm{~h}$ after cardiac arrest in patient 5 of our series who had consciousness recovery and CPC 1-2. Upper: cortical SSEP (C3'/C4'-Fpz). Note the increase in amplitude and the decrease in latency of the N20/P25 evoked potentials at $50 \mathrm{~mA}$ electrical stimulation (red line) with respect to the baseline (black line) at $10 \mathrm{~mA}$. Note also the appearance of ML-SSEPs (P55/N65 and P80/ $\mathrm{N} 90)$ at $50 \mathrm{~mA}$ stimulation on the left median nerve (red line). Lower: 8-channel electroencephalogram (EEG) (F3/F4-CZ, C3'/C4'-CZ, T3/T4-CZ, P3/P4-CZ) performed in the same session of SSEP. No significant background EEG pattern change is detected between baseline recordings (black lines) with respect to the stimulation at $50 \mathrm{~mA}$ (red lines)

increase the numbers of false positives [1, 18]. In this study, false positives are minimized both by stimulation on the median nerve by the needle electrodes and by the earliness of the neurophysiological assessment (mean of $33 \pm 22 \mathrm{~h}$ ), which reduces the risk of technical difficulties related to possible limb edema or sepsis [50]. Moreover, the earliness of neurophysiological assessment prevents the possible interference of deep sedative medications like pentobarbital, which seems to suppress ML and long-latency SSEP in patients with severe head injuries [51]. However, experimental studies on recruitment of A delta fibers, as related to the strength of electrical stimulus applied on the peripheral nerve, show that pentobarbital does not suppress ML-SSEP [28, 52]. Our previous experience showed that, in anesthetized patients, propofol and midazolam did not blunt the cortical reactivity of electrical stimulation of A delta nerve fibers on the median nerves [11]. Moreover, it is important to underline that, even if several studies have shown that a stimulation rate above $1.5 \mathrm{~Hz}$ is associated with a decrease in ML-SSEP amplitude, the $50 \mathrm{~mA}$ stimulation compensates for the suboptimal recording paradigm, which consists of a $100 \mathrm{~ms}$ time base and a $3.3 \mathrm{~Hz}$ stimulation rate $[53,54]$.

Finally, we considered electrical stimuli on the median nerve sulcus to be a reproducible and noninvasive method to activate the A delta nerve fibers for triggering evoked and spontaneous brain reactivity; indeed this technique provides a way to evaluate EEG reactivity simultaneously with SSEP recording. Moreover the pain-related methodology is more sensitive to multimodal stimulations (somatosensory, auditory and visual), as these stimuli are under the threshold of salience in patients with consciousness disorders [55]. 


\section{Multimodal neurophysiological prediction of neurological outcome}

From a neurophysiological point of view, simplified EEG patterns, SSEP (both SL and ML), PR, and BP reactivity constitute the key parameters that can quickly (within $72 \mathrm{~h}$ of CA) inform the prognostication of postanoxic coma because they are differently altered by ischemic injury with a cranio-caudal encephalic direction. Indeed, the finding of a normal or diffuse slowing EEG in the acute phase assumes the integrity of the brain structures that generate the spontaneous and evoked activity. While a benign reactive EEG pattern seems to be associated with $50 \mathrm{~mA}$ ML-SSEP (except for the presence of a neurological disease that alters the peripheral or central nerve transmission), $50 \mathrm{~mA} \mathrm{ML-}$ SSEP seems to not always be associated with a benign reactive EEG pattern, as this pattern can appear later. The fact that EEG can be more suppressed than SSEP by hypoxic insult [56], hypothermia and anesthesia [11-15] shows that these neurophysiological examinations investigate different levels of brain function. Indeed, summed postsynaptic potentials (which generate EEG patterns) depend much more on the oxygen supply than do thalamus cortical cells (which generate cortical SL-SSEP) [56]. To supplement this work, our data showed that ML-SSEP triggered by painful stimulation at $50 \mathrm{~mA}$ occurs much earlier than a benign and reactive EEG does. In other words, the $50 \mathrm{~mA} \mathrm{ML}-$ SSEPs stress the firing of the cortico-cortical interactions involved in pain perception (in the insula, SII, and cingulate cortex) independently of the spontaneous cortical activity hidden by the ischemic penumbra. In this way ML-SSEP seems to represent a higher-order complexity of the somatosensory afferent pathway sensing mode, and the recovery of normal spontaneous synaptic functions seems to be critical in the recovery of the sending mode through the efferent behavioral pathway. The reliability of $50 \mathrm{~mA}$ ML-SSEP in predicting preserved cortical connections is also confirmed by fMRI neuroimaging data. Patients who regained consciousness and had a good outcome showed the activation of brain areas involved in the detection of pain [32], as shown in Fig. 4, which represents the twelfth patient of our series.

Interestingly, the early absence of ML-SSEP after CA is a marker of EEG synaptic depletion associated with insufficient recovery of motor-behavioral function and an evolution towards a minimally conscious state [31, 32].

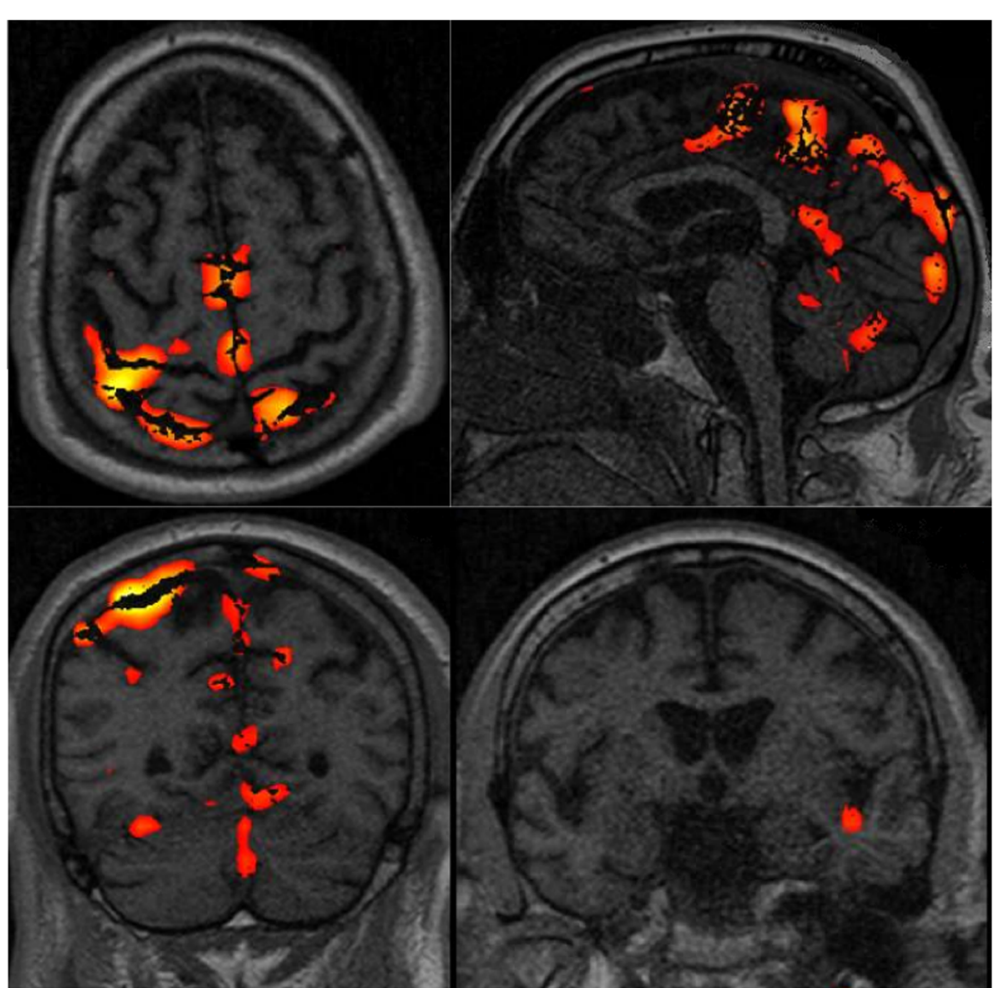

Fig. 4 Functional magnetic resonance imaging (fMRI) (21 days after cardiac arrest (CA)) of patient 12 of our series who had a good outcome, showing the brain activation of the somatosensory, motor, premotor, left insula and cerebellum areas. Some artifacts are also visible. The neurophysiological recording performed at $24 \mathrm{~h}$ after CA showed pain-related somatosensory evoked potentials (ML-SSEP) and a diffuse, slowing, nonreactive electroencephalogram (EEG). The subsequent EEG patterns were characterized by epilectiform activity. This patient regained consciousness at 33 days after CA 


\section{Limitations}

This study has some important limitations. First, the neurophysiologist reading the ML-SSEPs (and EEG) was not blinded to the patients' clinical status and outcomes. A multicenter prospective study should be carried out in order to share and validate this methodology and fully estimate the effectiveness of $50 \mathrm{~mA} \mathrm{ML-SSEP}$ in predicting neurological outcome in postanoxic patients. Further analysis should also consider ML-SSEP amplitude and laterality to better define long-term outcome and cognitive status while using a more detailed scale than CPC (e.g., Level of Cognitive Function, Coma Recovery ScaleRevised or neuropsychological evaluation). Moreover, we believe that the pain-related SSEP method could have false positive results if the patient suffers from A delta fibers disease. Finally, the impact of rehabilitation treatments on the final outcome of the patients should be evaluated.

\section{Conclusions}

This study shows that the combination of BP reactivity, PR, simplified EEG, SL-SSEP, and ML-SSEP constitute the key parameters that can quickly (within $72 \mathrm{~h}$ of CA) inform the prognostication of coma after CA. The Glasgow neurophysiological analog, obtained through the activation of ML cortical potentials with painful electrical stimulation on the median nerves, seems to detect the residual higher-order brain processing function. This predicts a good neurological prognosis earlier than EEG reactivity because this last one reflects the spontaneous electrical activity of brain areas that can be stunned by brain ischemia. Conversely, the absence of ML-SSEPs seems to be associated with a bad outcome. According to our opinion this method should be integrated into routine neurophysiological evaluation and used to funnel ICU treatments to patients with a good chance of recovery.

\section{Key messages}

- EEG, pupillary reflex, short- and middle-latency SSEP, and blood pressure reactivity constitute key parameters that can quickly (within $72 \mathrm{~h}$ of CA) inform the prognostication of postanoxic coma

- Middle-latency pain-related SSEPs detected early after a CA are associated with a good neurological prognosis in the absence of concomitant extra-neurological pathologies

- The prognostic capability of pain-related middle-latency SSEP was demonstrated to occur earlier than that of EEG reactivity

\section{Abbreviations}

AS: asystole; AUC: area under the curve; BPR: blood pressure reactivity CA: cardiac arrest; CAG: coronary angiography; CPC: cerebral performance category; CPR: cardiopulmonary resuscitation; $\mathrm{CWH}$ : continuous veno-venous hemofiltration; ECMO: extracorporeal membrane oxygenation; EEG: electroencephalogram; EMR: evaluation of motor response; fMRI: functional magnetic resonance imaging; GCS: Glasgow coma scale; IABP: intra-aortic balloon pump; ICU: intensive care unit; IHCA: in-hospital cardiac arrest; LUCAS: Lund University cardiac arrest system; ML-SSEP: middle-latency somatosensory evoked potentials; OHCA: out-of-hospital cardiac arrest; $\mathrm{PaCO}_{2}$ : partial pressure of arterial carbon dioxide; $\mathrm{PaO} 2$ : partial pressure of arterial oxygen; PEA: pulseless electrical activity; PIDS: patient's intravascular drug support; PR: pupillary reflex; PTCA: percutaneous transluminal coronary angioplasty; ROC: receiver operator characteristic; ROSC: return of spontaneous circulation; SII: secondary somatosensory area; SL-SSEP: short-latency somatosensory evoked potentials; TTM: target temperature management; VF: ventricular fibrillation; $\mathrm{VT}$ : ventricular tachycardia.

\section{Competing interests}

The authors declare that they have no competing interests.

\section{Authors' contributions}

PZ conceived of the study, acquired, collected and analyzed data, and drafted, revised and approved the final manuscript. FL collected data, performed the statistical analysis, analyzed data, and drafted the manuscript. APM and MA analyzed data and participated in the drafting of the manuscript. EB participated in the conceiving of the study and helped in the drafting of the manuscript. MB acquired and analyzed data and revised the manuscript. CS, CO, and MC participated in the discussion of the results and helped in the drafting of the manuscript. BS performed the statistical analysis, participated in the discussion of the results and helped in drafting the manuscript. All authors read and approved the manuscript.

\section{Acknowledgements}

We would like to thank the hospital management team of Treviso ULSS 9 and in particular Michele Tessarin, MD and Patrizia Benini, MD, for supporting neurophysiological research in the critical care area. We also thank Paolo Rosi, head of emergency service; Franco Marson, head of general intensive care; Valeria Salandin, head of cardiac surgery intensive care; Elvio Polesel, head of cardiac surgery; Zoran Olivari, Director of Cardiovascular Medicine Department; Paolo Boldrini, Director of Rehabilitation Medicine Department, and Francesco di Paola, Director of Radiology Department, for their support and help in collecting data. This work was done at the Department of Anesthesia and Intensive Care, Treviso Regional Hospital, IT.

\section{Author details}

${ }^{1}$ Department of Anaesthesia and Intensive Care, Intraoperative and Critical Care Neurophysiology in Cardiac Surgery, Treviso Regional Hospital, Azienda Ospedaliera Ulss 9, Piazzale Ospedale 1, 31100 Treviso, Italy.

${ }^{2}$ Neuromonitoring Project, Department of Anesthesia and Intensive Care, Treviso Regional Hospital, Piazzale Ospedale, 1, 31100 Treviso, TV, Italy. ${ }^{3}$ Unit of Neuroradiology, Treviso Regional Hospital, Piazzale Ospedale, 1, 31100 Treviso, TV, Italy. ${ }^{4}$ Department of Anesthesia and Intensive Care, Padova University Hospital, Via 8 Febbraio 1848, 2, 35122 Padova, PD, Italy. ${ }^{5}$ Department of Statistical Sciences, Padova University, Via 8 Febbraio 1848, 2, 35122 Padova, PD, Italy.

Received: 15 August 2015 Accepted: 28 October 2015

Published online: 17 November 2015

\section{References}

1. Bouwes A, Binnekade J, Kuiper M, Bosch F, Zandstra D, Toornvliet A, et al. Prognosis of coma after therapeutic hypothermia: a prospective cohort study. Ann Neurol. 2012;71:206-12.

2. Rossetti A, Oddo M, Logroscino G, Kaplan P. Prognostication after cardiac arrest and hypothermia: a prospective study. Ann Neurol. 2010;67:301-7.

3. Edgar A, Samaniego E, Mlynash M, Caulfield AF, Eyngorn I, Wijman C. Sedation confounds outcome prediction in cardiac arrest survivors treated with hypothermia. Neurocrit Care. 2011;15:113-9.

4. Thenayan E, Savard M, Sharpe M, Norton L, Young B. Predictors of poor neurologic outcome after induced mild hypothermia following cardiac arrest. Neurology. 2008;71:1535-7.

5. Wijdicks E, Hijdra A, Young G, Bassetti C, Wiebe S. Practice parameter: prediction of outcome in comatose survivors after cardiopulmonary resuscitation (an evidence-based review): report of the quality standards 
subcommittee of the American Academy of Neurology. Neurology. 2006;67:203-10.

6. Oddo M, Rossetti A. Early multimodal outcome prediction after cardiac arrest in patients treated with hypothermia. Crit Care Med. 2014;42:1340-7.

7. Cloostermans M, van Meulen F, Eertman C, Hom H, van Putten M. Continuous electroencephalography monitoring for early prediction of neurological outcome in postanoxic patients after cardiac arrest: A prospective cohort study. Crit Care Med. 2012;40:2867-75.

8. Rundgren $M$, Westhall $E_{1}$ Cronberg $T$, Rosn I, Friberg H. Continuous amplitude-integrated electroencephalogram predicts outcome in hypothermia-treated cardiac arrest patients. Crit Care Med. 2011;38:1838-44.

9. Legriel S, Hilly-Ginoux J, Resche-Rigon M, Merceron S, Pinoteau J, HenryLagarrigue $\mathrm{M}$, et al. Prognostic value of electrographic postanoxic status epilepticus in comatose cardiac-arrest survivors in the therapeutic hypothermia era. Resuscitation. 2013;84:343-50.

10. Sreedharan J, Gourlay E, Evans MR, Koutroumanidis M. Falsely pessimistic prognosis by EEG in post-anoxic coma after cardiac arrest: the borderland of nonconvulsive status epilepticus. Epileptic Disord. 2012;14:340-4

11. Zanatta P, Benvenuti SM, Bosco E, Baldanzi F, Longo C, Palomba D, et al. Intraoperative neurophysiological monitoring of the afferent pain pathway in cardiac surgery patients. Clin Neurophysiol. 2011;122:2093-9.

12. Deiner $\mathrm{S}$. Highlights of anesthetic considerations for intraoperative neuromonitoring. Semin Cardiothorac Vasc. 2010;14:51-3.

13. Wess C, Sarnthein J, Krayenbu N, Scholz M, Kunze E, Meixensberger J. Spectral IEEG markers precede SSEP events during surgery for subarachnoid hemorrhage. Clin Neurophysiol. 2010;121:2172-6.

14. Kochs E. Electrophysiological monitoring and mild hypothermia. J Neurosurg Anesth. 1995;7:222-8.

15. Newey C, Sarwal A, Hantus S. Continuous electroencephalography (CEEG) changes precede clinical changes in a case of progressive cerebral edema. Neurocrit Care. 2013;18:261-5.

16. Zhang Y, Su YY, Ye H, Xiao SY, Chen WB, Zhao JW. Predicting comatose patients with acute stroke outcome using middle-latency somatosensory evoked potentials. Clin Neurophysiol. 2011;122:1645-9.

17. Zhang Y, Wang M, Su YY. The role of middle latency evoked potentials in early prediction of favorable outcomes among patients with severe ischemic brain injuries. J Neurol Sci. 2014;345:112-7.

18. Zandbergen E, Koelman J, de Haan R, Hijdra A. SSEPs and prognosis in postanoxic coma. only short or also long latency responses? Neurology. 2006:67:583-6

19. Madl C, Kramer L, Domanovits H, Woolard R, Gervais H, Gendo A, et al. Improved outcome prediction in unconscious cardiac arrest survivors with sensory evoked potentials compared with clinical assessment. Crit Care Med. 2000;28:721-6.

20. Young GB, Doig G, Ragazzoni A. Anoxic-ischemic encephalopathy: clinical and electrophysiological associations with outcome. Neurocrit Care. 2005:2:159-64

21. Fischer C, Luauté J, Adeleine P, Morlet D. Predictive value of sensory and cognitive evoked potentials for awakening from coma. Neurology. 2004;63:669-73.

22. Logi F, Fischer C, Murri L, Mauguière F. The prognostic value of evoked responses from primary somatosensory and auditory cortex in comatose patients. Clin Neurophysiol. 2003;114:1615-27.

23. Prohl J, Röther J, Kluge S, de Heer G, Liepert J, Bodenburg S, et al. Prediction of short-term and long-term outcomes after cardiac arrest: a prospective multivariate approach combining biochemical, clinical, electrophysiological, and neuropsychological investigations. Crit Care Med. 2007;35:1230-7.

24. Bauer E, Funk GC, Gendo A, Kramer L, Zauner C, Sterz F, et al. Electrophysiological assessment of the afferent sensory pathway in cardiac arrest survivors. Eur J Clin Invest. 2003;33:283-7.

25. Wu D, Anastassios B, Xiong W, Madhok J, Jia X, Thakor NV. Study of the origin of short- and long-latency SSEP during recovery from brain ischemia in a rat model. Neurosci Lett. 2010;485:157-61.

26. Wu D, Xiong W, Jia X, Geocadin RG, Thakor NV. Short- and long-latency somatosensory neuronal responses reveal selective brain injury and effect of hypothermia in global hypoxic ischemia. J Neurophysiol. 2012;107:1164-71.

27. Frot M, Mauguiere F. Timing and spatial distribution of somatosensory responses recorded in the upper bank of the Sylvian fissure (SII area) in humans. Cereb Cortex. 1999;9:854-63.
28. Alpsan D. The effect of the selective activation of different peripheral nerve fiber groups on the somatosensory evoked potentials in the cat. Electroencephalogr Clin Neurophysiol. 1981;51:589-98.

29. Chudler EH, Dong WK. The assessment of pain by cerebral evoked potentials. Pain. 1983;16:221-44

30. Treede R, Apkarian A, Bromm B, Greenspan J, Lenz F. Cortical representation of pain: functional characterization of nociceptive areas near the lateral sulcus. Pain. 2000;87:113-9.

31. Zanatta P, Benvenuti SM, Baldanzi F, Bosco E. Pain-related middle-latency somatosensory evoked potentials in the prognosis of post anoxic coma: a preliminary report. Minerva Anesthesiol. 2012;78:749-56.

32. Zanatta P, Benvenuti SM, Baldanzi F, Bendini M, Saccavini M, Tamari W, et al. Pain-related somatosensory evoked potentials and functional brain magnetic resonance in the evaluation of neurologic recovery after cardiac arrest: a case study of three patients. Scand J Trauma Resusc. 2012;20:22.

33. Mouraux A, Diukova A, Lee MC, Wise RG, lannetti GD. A multisensory investigation of the functional significance of the "pain matrix.". Neuroimage. 2011:54:2237-49.

34. Downar J, Crawley AP, Mikulis DJ, Davis KD. A multimodal cortical network for the detection of changes in the sensory environment. Nat Neurosci. 2000;3:277-83.

35. Peberdy M, Callaway C, Neumar R, Geocadin R, Zimmerman J, Donnino M, et al. Post-cardiac arrest care: 2010 American Heart Association guidelines for cardiopulmonary resuscitation and emergency cardiovascular care science. Circulation. 2010;122:S768-86.

36. Jayakar P, Alvarez L, Duchowny M, Resnick T. A safe and effective paradigm to functionally map the cortex in childhood. J Clin Neurophysiol. 1992;9:288-93.

37. Ranck J. Which elements are excited in electrical stimulation of mammalian central nervous system: a review. Brain Res. 1975;98:417-40.

38. Teasdale G, Jennett B. Assessment of coma and impaired consciousness: a practical scale. Lancet. 1974:2:81-4

39. Ingvar M. Pain and functional imaging. Philos Trans R Soc Lond B Biol Sci. 1999:354:1347-58.

40. Holm S. A simple sequentially rejective multiple test procedure. Scand J Stat. 1979;6:65-70

41. Firth D. Bias reduction of maximum likelihood estimates. Biometrika. 1993:80:27-38

42. Kosmidis I, Firth D. Bias reduction in exponential family nonlinear models. Biometrika. 2009;96:793-804.

43. R Core Team. A language and environment for statistical computing Vienna, Austria: R Foundation for Statistical Computing; 2014. http://www.R-project.org/.

44. Nolan J, Laver S, Welch C, Harrison D, Gupta V, Rowan K. Outcome following admission to UK intensive care units after cardiac arrest: a secondary analysis of the ICNARC case mix programme data base. Anaesthesia. 2007:62:1207-16.

45. Stephenson H, Reid L, Hinton J. Some common denominators in 1200 cases of cardiac arrest. Ann Surg. 1953;137:731-42.

46. Fugate J, Rabinstein A, Wijdicks E. Blood pressure patterns after brain death. Neurology. 2011;77:399-401.

47. Grippo A, Carrai R, Fossi S, Cossu C, Mazzeschi E, Peris A, et al. Absent SEP during therapeutic hypothermia did not reappear after re-warming in comatose patients following cardiac arrest. Minerva Anestesiol. 2013;79:360-9.

48. Zanatta P, Bosco E, Comin A, Mazzarolo AP, Di Pasquale P, Forti A, et al. Effect of mild hypothermic cardiopulmonary bypass on the amplitude of somatosensory-evoked potentials. J Neurosurg Anesthesiol. 2014;26:161-6.

49. Robinson L, Micklesen P, Tirschwell D, Lew H. Predictive value of somatosensory evoked potentials for awakening from coma. Crit Care Med. 2003;31:960-7.

50. Leithner C, Ploner CJ, Hasper D, Storm C. Does hypothermia influence the predictive value of bilateral absent N20 after cardiac arrest? Neurology. 2010;12:965-9.

51. Newlon PG, Greenberg RP, Enas GG, Becker DP. Effects of therapeutic pentobarbital coma on multimodality evoked potentials recorded from severely head-injured patients. Neurosurgery. 1983;12:613-9.

52. Handwerker HO, Zimmermann M. Cortical evoked responses upon selective stimulations of cutaneous group 3 fibers and the mediating spinal pathways. Brain Res. 1972;28:437-40.

53. Delberghe X, Mavroudakis N, Zegers de Beyl D, Brunko E. The effect of stimulus frequency on post- and pre-central short latency somatosensory evoked potentials (SEPS). Electroencephalogr Clin Neurophysiol. 1990;77:86-92. 
54. Barba C, Frot M, Valeriani M, Tonali P, Mauguire F. Distinct fronto-central N60 and supra-Sylvian N70 middle-latency components of the median nerve SEPS as assessed by scalp topographic analysis, dipolar source modelling and depth recordings. Clin Neurophysiol. 2002;113:981-92.

55. Chatelle C, Thibaut A, Whyte J, De Val MD, Laureys S, Schnakers C. Pain issues in disorders of consciousness. Brain Inj. 2014;28:1202-8.

56. van Putten $\mathrm{M}$. The $\mathrm{N} 20$ in post-anoxic coma: are you listening? Clin Neurophysiol. 2012;123:1460-4.

Submit your next manuscript to BioMed Central and take full advantage of:

- Convenient online submission

- Thorough peer review

- No space constraints or color figure charges

- Immediate publication on acceptance

- Inclusion in PubMed, CAS, Scopus and Google Scholar

- Research which is freely available for redistribution 